\title{
Autoimmunity and non-accidental injury in children
}

\author{
Michael D Innis \\ Retired Haematologist, Princess Alexandra Hospital, Brisbane, Australia
}

Email address:

micinnis@bigpond.com(M. D. Innis)

\section{To cite this article:}

Michael D Innis. Autoimmunity and Non-Accidental Injury in Children. Clinical Medicine Research. Vol. 2, No. 3, 2013 , pp. 40-44. doi: 10.11648/j.cmr.20130203.15

\begin{abstract}
Background: The Shaken Baby Syndrome conceived by Guthkeltch to explain bruises, fractures, retinal and cerebral haemorrhage and encephalopathy in children, called the "triad", can be explained by an autoimmune reaction to antigens in a genetically susceptible child. Method: Children diagnosed as suffering from Non-accidental injuries were investigated for evidence of immune response reactions following mandated vaccination and childhood illnesses. Results: It was found in all the cases reported here the response to antigenic stimulation damaged the Beta cells in the Pancreas causing Hypoinsulinaemia which inhibited the cellular uptake of Vitamin $\mathrm{C}$ resulting in liver dysfunction, failure of carboxylation of the Vitamin K dependent proteins resulting in haemorrhages and fractures associated with the "triad". Conclusion: Fractures, retinal and subdural haemorrhages and encephalopathy in children - is an autoimmune response to antigenic stimulation in a genetically susceptible individual. Common antigens are the mandated vaccines, viral bacterial and parasitic infections.
\end{abstract}

Keywords: Shaken, Baby, Non-accidental, Injury, Triad

\section{Introduction}

A Psychologist, Ms Lisa Blakemore Brown, was the first to draw attention to the injustice caused by the medical profession's reliance on the diagnosis "Munchausen Syndrome by Proxy (MSBP)[1] when evaluating a mother's concerns for her child. This diagnosis served especially useful when the doctor could not explain a child's bruise or fracture and refused to accept the mother's version of events that the injuries followed mandated immunization[2].

A 15 year old boy was found dead in his bed a week before Christmas in 1994, 10 days after receiving the MR vaccine at school. An inquest held in 1995 concluded that he died from an epileptic fit, even though there had been no personal or family history of epilepsy. Northern Ireland Attorney General John Larkin QC, ordered a second inquest stating, "I consider it to be of enormous public importance that the possible role of the MR vaccine in the death of an apparently healthy boy be fully explored."[3]

Regarding the MMR/MR vaccine Wakefield and his colleagues were the first to reportmethylmalonic acid in the urine of autistic children and those with ASD who had been given the vaccine. Urinary mehylmalonic acid was significantly raised in all eight children who were tested, compared with age matched conrols $(p=0.003)[4]$.
Methymalonic acid in the urine is a marker of Viamin B12 deficiency resulting from an autoimmune destruction of the Parietal cells of the stomach which produce Intrinsic Factor required for the absorption of Vitamin B12 in the food. Vitamin B12 deficiency causes demyelination of the Central Nervous System and this explains the sensory, motor and psychological symptoms of autism and would also explain the death of the 15 year old boy.

Dr Jane Orient stated that mandatory vaccination is the leading edge of the new ethic. The policy to require annual influenza vaccination as a condition of working in a medical facility illustrates the dogmatism of the public health model and how it trumps individual autonomy, the Hippocratic ethic, and also evidence-based medicine[5] a view further explored here.

Dr Archivides “Archie” Kalokerinos, while a General Practitioner in rural Australia, observed that Aboriginal children when vaccinated with the mandated vaccines frequently developed the signs of scurvy and many died. He reduced the death rate by avoiding immunization of unwell children and by administering Vitamin $\mathrm{C}$ prior to vaccinating them. His book "Every Second Child"[6] records his experiences. He was the first to recognize the part played by vaccines as a cause of infantile scurvy. He said, "during one trial the prosecution said scurvy was no 
longer seen. I replied - Yes it is. But it is not called 'scurvy' it is called Shaken Baby Syndrome".

Professor Alan Clemetson related the signs and symptoms of the "triad" consisting of retinal haemorrhages, subdural haematoma and encephalopathy to histamineaemia following vaccination[7] and similar views had been expressed by Gardner[8]. These authors have provided alternative explanations for the "Shaken Baby Syndrome" theory postulated by Guthkelch[9] and their views are explored further.

\section{Method}

Here it is shown that vaccines, and other forms of antigenic stress damage the Beta cells of the islets of Langerhans and the resulting hypoinsulinaemia, manifested in these cases by hyperglycaemia, inhibits the cellular uptake of Vitamin $\mathrm{C}$ where it functions as an electron donor for important enzymes[10].causing "tissue scurvy"[11] - deficient Vitamin C in the cells. .

Normally insulin binds to its receptor on the cell surface and initiates a chain of events that leads to the insertion in the plasma membrane of a transmembrane glucose transporter called GLUT 4 which facilitates the transport of glucose and other nutrients into the cell[11]. It is the failure of this process, because of the lack of Insulin, which prevents the entry of Vitamin $\mathrm{C}$ into the cell and causes "tissue scurvy." Tissue scurvy, when it involves the cells of the liver leads to under carboxylation of the coagulation factors and osteocalcin resulting in bruises, haemorrhages and fractures[12].

This report explores the pathogenesis of the "triad" and concludes infections and antigenic stimulation of the immune system by vaccines do indeed play a major role in the pathogenesis of the "triad" by inducing autoimmune diabetes and associated Tissue Scurvy misdiagnosed as Shaken Baby Syndrome, Abusive Head Trauma, Inflicted Brain Injury and Non-accidental Injury.

\section{Results}

\subsection{Case 1}

A five month old infant, vaccinated with the usual mandated vaccines four weeks earlier, was fed by the father and put to bed. He was asleep for about 10-15 minutes before the father heard the infant gasping for breath. He immediately called the Emergency Medical Service.

The Ambulance arrived in about 10 minutes after the call and transported the child to the Hospital where a Clinical Investigation and Radiological examination revealed the child had suffered a subdural haematoma.

Blood Tests showed:

1. Prothrombin Time 17.3 seconds (control 11.9 - 14.2)

2. International Normalized Ratio (INR) 1.46 (control $0.89-1.12$ )

3. Glucose $102 \mathrm{mg} / \mathrm{dL}$ (control 65-95)
4. Creatinine $0.3 \mathrm{mg} / \mathrm{dL}$ (control $0.5-1.3$ )

5. Lactate $2.3 \mathrm{mmol} / \mathrm{L}$ (control $0.5-1.6$ )

6. BUN/Creatine 35 (control 10-20)

7. Total Haemoglobin $6.8 \mathrm{~g} / \mathrm{dL}$ (control 10.0-14.0)

8. Phosphorus $5.4 \mathrm{mg} / \mathrm{dL}$ (control $2.5-4.5 \mathrm{mg} / \mathrm{dL}$ )

Retinal haemorrhages were observed in the infant's left eye and the infant's injuries were diagnosed as evidence of the Shaken Baby Syndrome and reported by the Surgeon to the appropriate authority who instituted Legal Proceedings.

It is clear from the Blood Tests that this child needed urgent treatment of the Coagulation Disorder, Vitamin K Deficiency, from which he was suffering and Vitamin $\mathrm{K}$ was administered by intramuscular injection. Surgery was performed and the subdural haematoma removed. The child slowly recovered.

\subsection{Case 2}

The second child of a 34 year old mother was born by normal vaginal delivery and weighed $61 \mathrm{bs} 13 \mathrm{oz}$ she was breast fed and appeared to be progressing satisfactorily and was immunized with the mandated vaccines at the age of 3 weeks. Following this, at the age of 7 weeks the child began crying incessantly. The father attempted to comfort her but she suddenly became limp, stopped breathing and was rushed to hospital where resuscitation efforts were commenced.

Investigations included:

1. Skeletal survey which showed.

a Right parietal skull fracture

b Right 6th and 7th rib fractures

2. CT of brain

a 5mmright parietal temporal subdural haematoma

b Cerebral oedema.

3. Blood Tests

$\begin{array}{llc}\text { a } & \text { Albumin 2.2 gm/dL } & \text { control 2.8-5.0 } \\ \text { b } & \text { BUN/Creatine 50 } & 5-35 \\ \text { c } & \text { Glucose 347 mg/dL } & 70-105 \\ \text { d } & \text { Amylase 7 U/L } & 39-214 \\ \text { e } & \text { Lipase 13UL } & 22-51 \\ \text { f } & \text { Haemoglobin 7.9g/dL } & 9.0-12.3 \\ \text { g } & \text { Platelets 512 K/UL } & 295-465 \\ \text { h } & \text { Prothrombin Time 15.4 sec } & 11.5-14.0 \\ \text { i } & \text { Fibrinogen 148 mg/dL } & 180-490\end{array}$

4. Urine Tests
a Specific gravity 1.023
control $1.005-1.03$
b Glucose $>1000 \mathrm{mg} / \mathrm{dL}$
0.00

Resuscitation efforts included mechanical ventilation and endotracheal intubation but the infant expired after a period of 11 days.

An autopsy was performed and the result reads:"OPINION: It is our opinion that ----- , a 71/2 week old white female infant, died as a result of Craniocerebral Injuries. At autopsy injuries included a skull fracture with an overlying scalp contusion. There was evidence of subdural haemorrhages, subarachnoid haemorrhages as well as brain parenchymal injuries. 
A complete autopsy to include NeoGen studies, toxicology studies, microscopic tissue examination, and $\mathrm{x}$ rays was performed.

The manner of death is to be determined by the Justice of the Peace".

The document is signed by 5 doctors.

\subsection{Case 3}

The child was one of triplets born after a 32 week gestation and weighed $1560 \mathrm{gm}$. He was kept in the Intensive Care Unit, suffered from Respiratory Distress Syndrome and was placed on a respirator for three weeks. He was given an injection of Vitamin K shortly after birth.

He was Formula fed and his progress was satisfactory and at the age of 4 months he was given the routine vaccines. Eight days following his vaccination he became irritable and began crying and by the tenth day he was inconsolable and refused his feeds.

That evening the mother noticed him struggling for breath and he became limp, No time was lost in taking him to the nearest Hospital where a CT scan showed a right subdural haematoma.

A Blood Report showed:

1.Prothrombin Time 14.4 seconds Normal Range 10.8 13.7

2.PartialThromboplastinTime44.6seconds $26.1-35.0$

3.Platelets $491 \mathrm{~K} / \mathrm{mm} 3150-450$

4.Glucose $153 \mathrm{mg} / \mathrm{dL} \quad 70-110$,

B. Ophthalmoscopic Examination

Bilateral Retinal Haemorrhages

C. Skeletal Survey

No definite fractures either acute or old. However slight irregularity of the distal left ulnar metaphysis as well as a small lucancy through the lateral aspect of the distal right tibia.

According to the father the possibility of the child having a Non-accidental Injury was discussed because of the subdural haematoma, bilateral retinal haemorrhages and the irregular left ulnar metaphysis but it was not pursued as the child slowly recovered,

\subsection{Case 4}

\subsubsection{Birth Record}

This child was born via vaginal delivery after a gestation period of 31 weeks. She was placed in the Neonatal Intensive Care Unit and required Continuous Positive Airway Pressure. Her birth weight was 1300 grams.

Progress

Progress was satisfactory until at the age of 3 months, when 18 days following her routine immunizations, her mother noticed her mouth was bleeding and on looking into the infant's mouth saw a lesion under the tongue which she thought was due to Thrush. The mother gave her a dose of Tylenol but the child continued to be "fussy", had difficulty in breathing, and was taken to the hospital Emergency Room.
On examination she had an Oxygen saturation of $100 \%$ on room air, mild retractions, shallow breathing, tachypnoea, $6 \mathrm{~mm}$ tear distal to the frenulum without active bleeding,andpetechiae on the left arm and right thigh. Investigations

1. A pediagram showed multiple rib fractures, left tibial and left femur fractures.

2. Blood Chemistry

$\begin{array}{lll}\text { Creatinine } & 0.1 \mathrm{mg} / \mathrm{dLC} \text { Control } & 0.4-1.2 \\ \text { Glucose } & 113 \mathrm{mg} / \mathrm{Dl} & 70-99 \\ \text { Total Protein } & 5.7 \mathrm{~g} / \mathrm{dL} & 6.4-8.4 \\ \text { Albumin } & 3.4 \mathrm{~g} / \mathrm{dL} & 3.8-5.4 ? \\ \text { ALT } & 140 \mathrm{unit} / \mathrm{L} & 0-65 \\ \text { AST } & 46 \mathrm{unit} / \mathrm{L} & 0-37\end{array}$

\subsection{Case 5}

\subsubsection{Birth Record}

Carol, not her real name, the second child of a 24 year old mother who smoked throughout her pregnancy was born by spontaneous vaginal delivery at full term. Her Apgar scores were 8 at 1 minute, 10 at 5 minutes and 10 at 10 minutes and she weighed $2.79 \mathrm{~kg}$ and was given an intramuscular injection of Vitamin $\mathrm{K}$

Carol was Formula fed and appeared to be progressing satisfactorily when seen at her 6 week assessment where she received her 1 st immunizations of DTaP and Meningitis vaccine.

\subsubsection{Progress}

Three days after these immunizations she started vomiting and refused her feeds. The parents were concerned at the appearance of two small finger-tip bruises on her arm and took her to her GP who assured the parents there was no cause for alarm.

Carol continued to be sickly and was fed with difficulty and a visiting nursing note says, "feeding well with firm handling". Small frequent feeds were advised.

At the age of 6 weeks she was being fed by her father when she suddenly "spluttered some droplets of milk out of her mouth, made a strange wheezing noise as if she was both blowing and sucking at the same time. Her eyes started to shut and rolled back and she went limp and stopped breathing".

The Emergency Service were alerted and arrived within a few minutes and artificial respiration restored normal breathing. She was taken to the local Hospital where she was intubated and a series of investigations commenced.

\subsubsection{Radiology}

1. X-ray upper abdomen, chest and both obliques of the chest.

a Displaced healing fracture of the right clavicle

b Fractures of the 6th,7th, 8th and 9th ribs next to the spine.

2. Skull X-Ray Widening of the sutures. No fracture seen. 3. Brain Scan. Moderate parafalcine subdural haemorrhage 


\subsubsection{Blood Count}

$\begin{array}{lll}\text { Haemoglobin } & 9.1 \mathrm{~g} / \mathrm{dL} & \text { Normal Range 10.0-13.5 } \\ \text { Platelets } & 741 \times 109 / \mathrm{L} & 150 \text {---450 }\end{array}$

3.5.5. Coagulation Screen

$\begin{array}{lll}\text { Prothrombin Time } & 15.1 \mathrm{secs} & 8.2-14.1 \\ \text { Fibrinogen } & 1.6 \mathrm{~g} / \mathrm{L} & 1.70----4.0\end{array}$

3.5.6. Blood Chemistry

$\begin{array}{lll}\text { Albumin } & 28 \mathrm{~g} / \mathrm{L} & 35-55 \\ \text { Alkaline Phosphatase } & 321 \mathrm{U} / \mathrm{L} & 65---265 \\ \text { Alanine Transaminase } & 59 \mathrm{U} / \mathrm{L} & 5----45 \\ \text { Lactate } & 6.6 \mathrm{mmol} / \mathrm{L} & 1.1---2.2\end{array}$

\subsubsection{Urine}

Protein

Glucose

Blood

Trace by Multistix

+ by Multistix

Trace by Multistix

Attempts at resuscitation failed. A Post-mortem examination was carried out and death was attributed to Non-accidental Injury and the father was arrested and charged with the murder of the child.

\subsubsection{The Trial}

\subsubsection{Prosecution Witnesses}

1st Consultant Radiologist (Expert witness for the Prosecution)

"This child has suffered multiple episodes of physical injury including Rib fractures of three different ages in multiple sites due to squeezing. Metaphyseal limb fractures in multiple sites of at least two different ages due to gripping and twisting (or flailing) injuries.

An old clavicular fracture probably due to direct trauma.

A subdural haematoma due to shaking(and/or impact if fracture is proven) in the day prior to collapse at home

A final event leading to cardiorespiratory arrest at home, leading to death."

\subsubsection{2nd Consultant Radiologist}

"In my opinion, the total constellation of the injuries is entirely typical of non-accidental injury and that is taking into account the mechanism of causation of most of the injuries"

\subsubsection{Consultant Haematologist}

"There are no haematological disorders which would explain the bony abnormalities in this child."

\subsubsection{Defence Witnesses}

Reduced levels of Albumin and Fibrinogen together with Increased Alanine Transaminase is evidence of Liver dysfunction and the Increase in ProthrombinTime is supportive evidence of a deficiency of Vitamin K and the fractures and the haemorrhages are attributable to Vitamin K Deficiency[12]

\subsubsection{Verdict}

The Judge recognized the father as a loving caring honourable man who would never injury anyone; least of all his own child and he dismissed the charge and recorded a verdict of Not Guilty.

In cases such as this, when the Judge is presented with opposing "Expert" opinions, it would seem fair to accept the evidence of the accused as it is impossible for anyone untrained in the subtleties of differential diagnosis to assess the relevance of either the argument of the prosecution or that of the defence.

This is a classic example of the current "main stream" Radiological and Haematological views which ignore the possibility of a deficiency of Vitamin $\mathrm{C}$ or $\mathrm{K}$ as the cause of both fractures and haemorrhage in a child in spite of the clear evidence of a nutritional defect.

\section{Interpretation}

In all four cases shown here there is evidence that hyperglycaemia followed vaccination and hyperglycaemia implies hypoinsulinism, an autoimmune disorder resulting from the destruction of the Beta cells of the pancreas. Since insulin is required for the transfer of vitamin $\mathrm{C}$ into the cells the intracellular vitamin $\mathrm{C}$ is reduced[12]. The resulting "tissue scurvy" compromises the function of the Liver by inhibiting carboxylation of the clotting and bone forming factors and is manifested as the signs and symptoms of the "triad".

Both Dr Kalokerinos and Professor Clemetson recommended giving the infant Vitamin $\mathrm{C}$ before vaccination but it would seem more appropriate to do an intradermal skin test to test for sensitivity in every case. Both were firmly of the view that a metabolic abnormality of Vitamin $\mathrm{C}$ was the essential cause of the signs and symptoms of the alleged "Non-accidental injuries".

Contrary views have recently been expressed by Sheets, L. K. et al 2013.Sentinel Injuries in Infants Evaluated for Child Physical Abuse, Pediatrics, 11 March.http://pediatrics.aappublications.org/content/early/2 013/03/06/peds.2012-2780and by Dr Angelo P Giardino in Medscape April 12013.

Both these reports repeat the arguments of their predecessors without providing any scientific evidence for their opinions.

While the only antigen examined in these findings is limited to mandated vaccines it is clear that numerous viral, bacterial, parasitic and chemical antigens could generate an autoimmune response and affect other tissues such as the nervous system and cause Autism.

I conclude the warnings of Ms Lisa Blakemore Brown to ignore the Munchausan Syndrome By Proxy is sound advice and the views of $\mathrm{Dr}$ Archie Kalokerinos and Professor Alan Clemetson on the subject of "unexplained injuries" are valid and it is time the governments of the UK, USA, Canada and Australia ban the diagnoses Shaken Baby Syndrome and any of its "morphs" and restore Justice to the Legal Systems of the Country. 


\section{Acknowledgments}

I wish to acknowledge the help I received from the late Professor Alan Clemetson and the late $\mathrm{Dr}$ Archie Kalokerinos both of whom sent me copies of their publications. I also wish to thank the parents of the children reported here who provided me with the information recorded.

\section{References}

[1] Medows R. "Munchausen Syndrome By Proxy The Hinterland of Child Abuse"Lancet, Volume 310, Issue 8033, Pages 343 - 345, 13 August 1977

[2] Lisa Blakemore-Brown, "Consultation document on MSBP"http://bmj.bmjjournals.com/cgi/eletters/323/7308/29 6\#16022

[3] Struthers M A "Foolish faith in authority is the worst enemy of truth". BMJ 2013: 346; 12830

[4] Wakefield AJ, Murch SH, Anthony A, LinnellJ,Casson DM, Malik M, et al;'Ileal-lymphoid-nodular hyperplasia, nonspecific colitis, and pervasive developmental disorder in children" Lancet vol 351. Feb 28 1998. (Retracted)

[5] Orient JM. "Mandatory Influenza Vaccination for Medical Workers a Critique". Jour AmerPhys\& Surg; 2012; 111-117
[6] Kalokerinos A. "Every Second Child" Thomas Nelson (Australia) Limited 1974

[7] Clemetson CAB. "Vaccinations, Inoculations and Ascorbic Acid". Jour Ortho Mol Med 1999; 14: 137 -142

[8] Gardener HB. "Immunizations, retinal and subdural hemorrhages: are they related?" Med Hypotheses 2005: 64; 663-664

[9] Guthkelth AN. "Infantile subdural haematoma and its relationship to whiplash injuries." BMJ 1971; ii: 430-1

[10] Levine M, Rumsey SC, Wang Y, Park JB, Daruwala R (2000). "Vitamin C. In Stipanuk MH. Biochemical and physiological aspects of human nutrition. Philadelphia:" W.B. Saunders. pp. 541-67. ISBN 0-7216-4452-X.

[11] Cunningham JJ. "The Glucose/Insulin System and Vitamin C:Implications in Insulin-dependent Diabetes Mellitus." J Am CollNutr; 1998: vol 17 p105-108

[12] Innis MD. "Vitamin K Deficiency Disease". Jour of Orthomol Med 2008; vol 23; 15-20

[13] Cunningham JJ, Ellis SL, McVeigh KL, Levine RE, Jorge CaliesEscandon"Reduced mononuclear leucocyte ascorbic acid content in adults with insulin-dependent diabetes mellitus consuming adequate dietary vitamin C." Metabolism 1981; vol 40; 148-149. 